\title{
Sublethal Toxicity of Acid Orange 7 in the Freshwater fish, Anabas testudineus (Bloch, 1792), and the Role of Vitamin C as Antioxidant in the Prevention of Oxidative Stress
}

\author{
C. V. Priyatha ${ }^{1}$, K. C. Chitra ${ }^{2 *}$ \\ ${ }^{1}$ Endocrinology and Toxicology Laboratory, Department of Zoology, University of Calicut, Kerala, India \\ ${ }^{2}$ Endocrinology and Toxicology Laboratory, Department of Zoology, University of Calicut, Kerala, India \\ *Corresponding Author: kcchitra@yahoo.com, Tel.: +91-94951-35330
}

Available online at: www.isroset.org

Received: 07/Mar/2019, Accepted: 11/Apr/2019, Online: 30/Apr/2019

\begin{abstract}
Sublethal toxic effects of acid orange 7 on antioxidant status and histology of liver, kidney and muscle tissues, and the protective role of vitamin C were examined in Anabas testudineus. Acid orange 7 at $0.27 \mathrm{~g} / \mathrm{L}$ concentration was exposed for 24,72 and $96 \mathrm{~h}$ followed by vitamin $\mathrm{C}(0.55 \mathrm{~g} / \mathrm{L}$ concentration) for 7 days. Activities of superoxide dismutase, catalase, glutathione reductase, and levels of hydrogen peroxide $\left(\mathrm{H}_{2} \mathrm{O}_{2}\right)$ generation and lipid peroxidation (LPO) were evaluated in the liver, kidney and muscle tissues. The results showed significant $(\mathrm{P}<0.05)$ reduction in the activities of antioxidant enzymes with concomitant increase in the levels of $\mathrm{H}_{2} \mathrm{O}_{2}$ and LPO thereby indicated the induction of oxidative stress. Activities of alanine and aspartate aminotransferases in liver and kidney, and acid and alkaline phosphatase in muscle tissue also decreased significantly $(\mathrm{P}<0.05)$ in the treatment groups due to the sublethal toxicity of acid orange 7 . Histopathological examination revealed severe damage in all tissues however, the damage was not fully recovered after vitamin $\mathrm{C}$ exposure. Interestingly, vitamin $\mathrm{C}$ exposure neutralized the toxic effects of acid orange 7 as evident by normalizing the activities of all antioxidant enzymes thereby proved the protection of tissues against oxidative stress.
\end{abstract}

Keywords - Acid orange 7, Vitamin C, Anabas testudineus, Oxidative stress, Sublethal toxicity, Histology

\section{INTRODUCTION}

Pollutants are the contaminants released directly or indirectly into the water bodies without adequate treatment for the removal of toxic compounds present in it. The effects of pollutants not only damage the individual species, but the whole population or the entire ecosystem. Modern agriculture, rapid industrialization, urbanization, pharmaceuticals, and discharge of untreated effluents are some of the serious concerns that challenge the humanity for the supply of basic needs in the form of water. World Health Organization has reported that $80 \%$ of all human illness in the developing countries is associated with water pollution and lead to worldwide cause of deaths [1]. A special report on India in 2008 has estimated that more than 1000 children die of diarrhea and other waterborne diseases every day. Various factors like water temperature, turbidity, nutrient, hardness, alkalinity, and dissolved oxygen play important role to keep the aquatic environment in balance. Recent decline in the natural fish population is due to the increased fishing pressure and various anthropogenic activities including aquatic pollution, and loss of natural habitat for spawning and growth [2].
Many pollutants in the aquatic environment are highly persistent, bioaccumulative, and toxic, while some are biomagnified to extraordinary degrees in food chains so as to reach humans and other animals. Lipophilic nature of toxicants enables to get concentrated in human breast milk, saliva, urine, blood sample and semen. Thus aquatic pollutants are extremely toxic to fish and other aquatic organisms, and also harm birds and humans that prefer fish as food. In India, small unrecognized industrial sector contribute to a great deal of water pollution. Millions of liters of sewage that originate from industrial, domestic and agricultural waste are discharged into the aquatic bodies in India. It is considered that accumulation of low concentrations of chemicals for prolonged period or high concentrations of chemicals for acute duration is toxic to aquatic organisms, and cause damages to aquatic environment. Currently on average only $20-30 \%$ of the waste water generated from industries of both rural and urban areas are treated. The untreated sewage are generated at $90 \%$ from rural and 50\% from urban regions as municipal waste, industrial pollutants, fecal load, fertilizers or pesticides, and as nuclear wastes produced from industrial, medical and scientific processes [3]. Apart from aquatic effluents and municipal wastewater, even the extracts 
derived from botanicals, surfactants, metals, radioactive materials, persistent organic pollutants, pharmaceuticals, endocrine disruptors, pesticides, petroleum hydrocarbons, polycyclic aromatic hydrocarbons, mining effluents, and nanomaterials are some of the toxic environmental contaminants. Though the growth of industries is considered as a vital factor to improve the quality of human life, the constant release of toxicants from such industries pollute water and cause numerous health hazards to aquatic organisms. Among the industries, textile industry play an important role for aquatic pollution as different coloring agents like dyes, inorganic pigments, tannins, lignins, etc used as colorants for painting, dyeing of clothes, hair and skin are of great concern [4].

Dyes are important in many industrial and consumer products for food coloring, paper production, personal care products, leather tanning, textiles and paints, however, the untreated effluents cause potential harmful effects to the environment and the organisms. Currently, there is little information regarding azo dye toxicity in humans as well as in aquatic environment and hence further studies are warranted [5]. In aquatic ecosystem, fishes are exposed to multiple pollutants that are known to alter several biochemical and physiological processes leading to the generation of reactive oxygen species (ROS) and induction of oxidative stress. Reactive oxygen species are capable of oxidizing macromolecules of cells, which damage cell structure and function, and finally lead to cell death [6] [7] [8] [9]. Enzymatic antioxidants such as superoxide dismutase (SOD), catalase (CAT), glutathione reductase and glutathione peroxidase play important role on the cellular defence mechanism against the toxicant-induced oxidative stress. Thus the biochemical approach of evaluating oxidative stress has been advocated to provide an early warning of exposed pollutants in stressed fish.

The role of oxidative stress as biomarkers has rapidly increased in the field of ecotoxicology and used widely in environmental monitoring systems [10]. Researches in fish have demonstrated that mammalian and piscine systems exhibit similar toxicological and adaptive responses to oxidative stress. Thus piscine models are used in toxicology, in addition to traditional mammalian models, for further understanding on the mechanisms underlying the oxidative stress response. In a recent study, starvation induced oxidative stress response has been revealed by the alteration in the antioxidant enzyme activity, increased gene expression of heat shock protein 70 and level of cortisol in fingerlings of Labeo rohita [11].

Fish is used as bioindicator species in ecotoxicological studies that reflect the health status of aquatic ecosystems, besides it is also serves as important food stuff to human. Thus evaluating the health status of fish population is essential to uplift the economy of nation. Anabas testudineus is a widely distributed fish throughout Indian water bodies which can survive in a highly polluted habitat. The present study focused on the biochemistry of oxidative stress marker in liver, kidney and muscle tissues in order to reveal the primary effects of toxicants in detoxification, excretion and metabolism of fish. Detoxification and antioxidant responses in liver tissues are most studied in fish while kidney perform important function in relation to electrolyte and water balance, and also maintain stable internal environment [12] [13]. Fish muscle, the most protein-rich edible part, is considered as the major target tissue against the toxicant as it is involved in metabolism and storage of chemicals.

Toxicological studies on the effect of acid orange 7 in fish remain scanty, and the present study attempted to investigate the sublethal toxicity of the azo dye on the induction of oxidative stress in the liver, kidney and muscle tissues of the fish, Anabas testudineus. Further the organ level toxicity was assessed by histopathological examination and tissuespecific marker enzymes. The study also examined the protective role of vitamin $\mathrm{C}$, a natural water-soluble antioxidant on the toxicity induced by acid orange 7 in the exposed fish. The present study may provide basic information on the negative impact of azo dyes in the aquatic ecosystem.

\section{RELATED WORK}

Amaya et al. (2018) worked on "Haematological responses in the freshwater fish, Anabas testudineus (Bloch, 1792) exposed to sublethal concentration of acid orange 7".

Shinjina et al. (2018) worked on "Ameliorating effect of vitamin $\mathrm{C}$ on oxidative stress induced by acid orange 7 in the gill of the fish, Anabas testudineus".

Rishin et al. (2019) worked on "Induction of genetic damage in peripheral erythrocytes of the fish, Anabas testudineus exposed to sublethal concentration of acid orange 7 ".

\section{METHODOLOGY}

\section{Acclimatization of fish:}

Mature teleostian fish, Anabas testudineus, weighing $7 \pm 1 \mathrm{~g}$ and length $7 \pm 1.5 \mathrm{~cm}$ were collected from the fish farm, Pulimukham Hatcheries, Alappuzha District, Kerala, India. Fish were acclimatized to the laboratory conditions prior to the experiment in dechlorinated, aerated, static water $(40 \mathrm{~L}$ capacity) and photoperiod of light and dark (12 h: 12h) was maintained throughout the study.

Preliminary tests, such as the physicochemical features of the tap water were estimated as per APHA guidelines, 1998 [14]. Water temperature in the experiment ranged from $26 \pm$ 
$2^{\circ} \mathrm{C}$, oxygen saturation of water maintained between 70 and $100 \%$ and $\mathrm{pH}$ at 7.4 to 7.6 , which were monitored throughout the study using the standardized procedures.

\section{Chemicals:}

Acid orange 7 (CAS-633-96-5) of 97\% purity was purchased from Tokyo Chemicals Industry (TCI) Private Limited, India. Vitamin C (ascorbic acid), malondialdehyde, pyrogallol, reduced glutathione, horseradish peroxidase, phenol red, NADPH, p-nitrophenyl phosphate, 2oxoglutarate, DL-alpha-alanine, 2,4-dinitrophenyl hydrazine were obtained from Himedia Research Laboratories, Mumbai, India. All other chemicals were of analytical grade and obtained from local commercial sources.

\section{Grouping of fish:}

In the experiment, one-tenth of median lethal concentration of acid orange 7 was chosen as sublethal concentration i.e., $0.27 \mathrm{~g} / \mathrm{L}$. Single concentration of the test chemical was exposed at different durations such as 24,72 and $96 \mathrm{~h}$ along with control group, without toxicant, by maintaining the sample size of ten fish specimens. Vitamin $\mathrm{C}$, a natural antioxidant, was exposed as a positive control after $96 \mathrm{~h}$ of the toxicant exposure, for 7 days in order to evaluate the protective role of vitamin $\mathrm{C}$ on the dye exposed fish.

\section{Preparation of tissues:}

Fish were sacrificed by decapitation, and liver, kidney and muscle tissues were immediately dissected out, cleaned from debris and weighed. Tissue homogenates (1\% w/v) of liver, kidney and muscle were prepared in cold normal saline using a motor driven tissue homogenizer. The homogenates were centrifuged at $800 \mathrm{~g}$ for $15 \mathrm{~min}$ at $4^{\circ} \mathrm{C}$ and the supernatants collected were used for the biochemical analyses.

\section{Biochemical analyses:}

Activities of superoxide dismutase [15], catalase [16], glutathione reductase [17] and the levels of hydrogen peroxide generation [18] and lipid peroxidation [19] were assayed in liver, kidney and muscle tissues. The activities of tissue marker enzymes namely aspartate aminotransferase (AST), alanine aminotransferase (ALT) were determined in liver and kidney tissues [20] whereas the activities of alkaline phosphatase (ALP) and acid phosphatase (ACP) were measured in muscle tissues [21]. Total protein in all tissues were analysed using bovine serum albumin as standard [22] in both control and treatment groups.

\section{Histopathological tests:}

Liver, kidney and muscle tissues were dissected from control, vitamin $\mathrm{C}$ exposed for 7 days, and acid orange 7 exposed for $96 \mathrm{~h}$ durations. Tissues were then fixed in buffered formalin for $48 \mathrm{~h}$, rinsed in a graded series of ethanol for dehydration, cleared in xylene, embedded in paraffin wax. Tissues were sectioned at $5 \mu \mathrm{m}$ thickness and stained with hematoxylin and eosin which were then mounted in DPX [23]. The histological alterations of each tissue were observed and photographed using a Canon shot camera fitted to the Carl Zeiss Axioscope-2 plus Trinocular Research Microscope.

\section{Statistical analyses:}

Biochemical data are expressed in Mean \pm standard deviation (SD) for ten animals per group. The mean differences were considered to be significant at $\mathrm{P}<0.05$ against the control group using one-way Analysis of Variance (ANOVA) test followed by Duncan's Multiple Range as post-hoc test. The analyses were performed using SPSS 21.0 as statistical tool. All biochemical analyses were carried out in duplicate to minimize statistical errors.

\section{RESULTS}

\section{Effect of acid orange 7 on tissue weights:}

Sublethal concentration $(0.27 \mathrm{~g} / \mathrm{L})$ of acid orange 7 significantly $(\mathrm{P}<0.05)$ decreased the weights of liver and kidney tissues after 24, 72 and $96 \mathrm{~h}$, whereas treatment of vitamin $\mathrm{C}$, showed no significant changes (Figure 1).

\section{Effect of acid orange 7 on enzymatic antioxidants:}

The activities of antioxidant enzymes such as superoxide dismutase, catalase, and glutathione reductase decreased significantly $(\mathrm{P}<0.05)$ in liver, kidney and muscle tissues in a time-dependent manner (Table 1). Exposure to vitamin $\mathrm{C}$ after the dye exposure for 7 days showed increase in all antioxidant enzymes and the results were similar to the untreated control group (Table 1).

\section{Effect of acid orange 7 on the levels of hydrogen} peroxide generation and lipid peroxidation:

Acid orange 7 exposure showed significant $(\mathrm{P}<0.05)$ increase in the levels of hydrogen peroxide generation and lipid peroxidation in liver, kidney and muscle tissues when compared to the corresponding control group. Vitamin $\mathrm{C}$ exposure retained the levels of hydrogen peroxide generation and lipid peroxidation similar to the level of control tissues (Figures 2 and 3).

\section{Effect of acid orange 7 on tissue marker enzymes:}

The activities of alanine and aspartate aminotransferase enzymes decreased significantly $(\mathrm{P}<0.05)$ in time-dependent 
manner in kidney whereas no significant changes were observed after $24 \mathrm{~h}$ in liver tissues. However, the activities of both enzymes decreased significantly $(\mathrm{P}<0.05)$ after 72 and $96 \mathrm{~h}$ of acid orange 7 exposure in liver tissues than the respective control groups (Figures 4 and 5). In muscle tissues, the activities of acid and alkaline phosphatase enzymes decreased significantly $(\mathrm{P}<0.05)$ in time-dependent manner (Figure 6). Exposure to vitamin $C$ showed the activities of all tissue marker enzymes similar to that of the corresponding control tissues (Figures 4-6).

\section{Effect of acid orange 7 on histology of tissues:}

Liver, kidney and muscle tissues of the control groups showed normal histoarchitecture (Figures 7a, 8a and 9a). Acid orange 7 exposed for $96 \mathrm{~h}$ showed prominent alterations in liver tissues such as degenerated and necrotic hepatocytes, and absence of nucleus (Figure 7b). Vitamin C exposure for 7 days after acid orange 7 exposure for $96 \mathrm{~h}$ showed prominent nucleus in the hepatocytes but the severity of tissue damage was not fully recovered (Figure 7c). Kidney tissue showed degeneration and necrosis of the tubule, and severe thrombosis (Figure 8b). Alterations in kidney tissue showed slight recovery after vitamin $\mathrm{C}$ exposure but the necrosis in tubule was retained in certain regions of the tissue (Figure $8 \mathrm{c}$ ). The histomorphological changes induced by sublethal exposure of acid orange 7 in muscle tissues were evident by flaccid and degenerated muscles (Figure 9b). Vitamin $\mathrm{C}$ exposure did not fully recover the alterations in the muscle tissues (Figure 9c).

\section{Discussion}

In the present study, the possible effects of acid orange 7 on the antioxidant status of liver, kidney and muscle tissues in the fish, Anabas testudineus was evaluated. One of the most significant and interesting topic of ecotoxicology is the potential role of oxygen-free radicals and other reactive oxygen species (ROS) generated from toxicant exposure that damage tissues and cellular components causing oxidative stress. Exposure to azo dyes creates great concern for aquatic life because of the nature of persistence, toxicity, bioaccumulation and amplification through food chain. In textile industry, during dyeing process about $10 \%$ of dyestuff do not bind to the fibers and thus released to the aquatic environment without being treated. Microbial decolourization is possible in many dyestuffs, but acid orange 7 is not completely degraded and the residues of degradation products are known to damage the water quality [24]. Even the degradation products are toxic to aquatic organisms and render the water unfit for aquatic life and human use.

In ecotoxicology, the selection of model organisms for toxicity test is mainly based on several criteria such as ecological status, position within the food chain, suitability for laboratory studies, genetic stability, uniform populations and adequate background data on the organism. Fish are among the group of aquatic organisms, which represent the largest and most diverse group of vertebrates. A number of characteristics formulate fish as an excellent experimental model for toxicological research, especially for the evaluation of pollutants and their impacts on aquatic ecosystems [25]. Fish, one of the most important members of the aquatic food chain, reaches the human along with numerous environmental contaminants.

The sublethal concentration $(0.27 \mathrm{~g} / \mathrm{L})$ of acid orange 7 was selected in the present study to evaluate the sublethal toxicity. The present study also evaluated the protective role of vitamin $\mathrm{C}$ on acid orange7 induced oxidative stress in liver, kidney and muscle tissues. Treatment-related decrease in the weight of animal observed in all experimental groups reflected the systemic toxicity of the dye exposure for a short period of $96 \mathrm{~h}$. The dye exposed fish recovered to a great extent when vitamin $\mathrm{C}$ at $0.55 \mathrm{~g} / \mathrm{L}$ concentration was treated for 7 days. Analysis of tissue weights is an important parameter in toxicological experiments in order to assess the effects of toxicants on specific organs. Exposure of acid orange 7 decreased the weights of liver and kidney tissues thereby reflected the severe tissue damage, whereas exposure to vitamin $\mathrm{C}$ for 7 days after the dye exposure recovered the weight of tissues.

The role of oxidative stress as biomarkers is a rapidly increasing field in aquatic ecotoxicology studies so as to monitor the impact of toxicants in aquatic ecosystems [26]. In all living cells, there is a constant production of reactive oxygen species (ROS) that occurs by the univalent reduction of oxygen molecule. About $5 \%$ or more of the inhaled oxygen is converted to ROS such as superoxide anion radical $\left(\mathrm{O}_{2}^{-}\right)$, hydrogen peroxide $\left(\mathrm{H}_{2} \mathrm{O}_{2}\right)$, and hydroxyl radical $\left({ }^{\circ} \mathrm{OH}\right)$ [27]. The balance between endogenous and exogenous pro-oxidant factors like environmental pollutants and enzymatic or non-enzymatic antioxidant defenses in biological systems is used to assess adverse effects of toxicants. Any imbalance in the pro-oxidant and antioxidant defense system result in a condition called oxidative stress [28]. Thus to attenuate the adverse effects of ROS, fish possess antioxidant defensive mechanism as several enzymatic and non-enzymatic products similar to other vertebrates. The enzymatic system includes superoxide dismutase, catalase, glutathione peroxidase, and glutathione reductase [29].

The present data showed decrease in the activities of superoxide dismutase, catalase, and glutathione reductase in liver, kidney and muscle tissues in a time-dependent manner. Functional insufficiency of enzymatic antioxidants was correlated to the concomitant increase in the levels of hydrogen peroxide generation and lipid peroxidation. The hydroxyl radicals formed after exposure to acid orange 7 
also contributed to increase in the level of lipid peroxidation, which generates a constellation of products that are reactive electrophiles as epoxides and aldehydes [30]. Malondialdehyde is a main secondary lipid oxidation product of polyunsaturated fatty acids in lipoproteins that are essential to the entire cell supporting system [31]. The elevated production of malondialdehyde after the dye exposure reflected the disruption in the structural properties of lipid membrane which consequently alters the cellular functions of liver, kidney and muscle tissues. Thus molecular mechanisms of antioxidant defense against oxidative modifications of lipids have great relevance in cell membranes of fish. Hydrogen peroxide formed as a result of dye exposure also react with membrane lipids and form lipid hydroperoxides which decomposes double bonds of unsaturated fatty acids, that disturb membrane stability and enhanced lipid peroxidation [32]. Therefore, increase in lipid peroxidation in muscle, kidney and liver tissue clearly demonstrated that sublethal exposure of acid orange 7 induced oxidative stress [33]. In the present study, vitamin C exposure was found to have an ameliorating effect of dye toxicity by enhancing the activities of antioxidant enzymes and declining the levels of hydrogen peroxide and lipid peroxidation near to the control tissues. Thus vitamin $\mathrm{C}$ protects the tissues from oxidative imbalance caused by acid orange 7 in the fish Anabas testudineus. The biochemical approach of evaluating oxidative stress can be used as a bioindicator to provide an early warning signal of dye exposed fish in the natural environment.

The activities of tissue-specific marker enzymes serve as a diagnostic tool to evaluate stress associated with the chemical toxicity. Alanine and aspartate aminotransferase enzymes are widely used as tissue markers of muscle, kidneys, liver, heart, gills, and other organs. The presence of tissue injuries or organ dysfunctions is associated with the alteration in the activities of tissue-specific marker enzymes, and therefore known to have clinical importance [34]. In the present study, determination of tissues level of alanine and aspartate aminotransferases are used to assess the toxic impact of acid orange 7 in kidney and liver. Acid orange 7 exposure showed a marked decline in the activities of alanine and aspartate aminotransferase in kidney and liver tissues of Anabas testudineus, which was time-dependent. The reduction in the enzyme activities indicated tissue damage and, also reflected the inability of kidney and liver tissues for the biosynthesis of enzymes as a result of acid orange 7 exposure or due to the inhibition of enzyme activity after the dye exposure. The same observations were found after dietary ochratoxin intoxication in the liver of African catfish [35]. On the other hand, vitamin C exposure enhanced the activities of alanine and aspartate aminotransferase enzymes to reach the level similar to that of unexposed fish. Thus vitamin $\mathrm{C}$ performed protective role by efficiently reducing the toxicity of acid orange 7 thereby enhanced the tolerance of fish against the dye exposure.

The activities of acid and alkaline phosphatase enzymes decreased in muscle tissues in response to the timedependent exposure of acid orange 7. Phosphatases are hydrolytic enzymes used as good indicator of stress-related toxicity in the biological systems [36]. Phosphatases are involved in the process of transphosphorylation and have significant role in the synthesis of proteins, transport of metabolites, metabolism of phospholipids, phosphoproteins, nucleotides and carbohydrates [37]. Decline in the activity of acid phosphatase reflected the uncoupling of phosphorylation, or increased glycogenolysis, or due to the alteration in the function of mitochondrial membrane in the muscle tissue [38]. Alkaline phosphatase enzyme was found in all tissues of fish that functions to mediate membrane transport by splitting various phosphate esters at an alkaline $\mathrm{pH}$ [39]. Sublethal exposure of acid orange 7 inhibited the activity of alkaline phosphatase thereby reflected an altered membrane transport, which in turn could lead to the breakdown of glycogen to meet energy demand as a result of dye intoxication. Besides, the exposure of acid orange 7 might have caused such enzymatic changes by the interaction of toxicant with co-factors and regulators so as to inhibit the enzyme biosynthesis. The present observations were in agreement with another study on exposure to an azo dye, Eriochrome black T, declined the activities of acid and alkaline phosphatase in gill of the fish, Labeo rohita [40]. However, vitamin $\mathrm{C}$ exposure brings the activities of acid and alkaline phosphatase to normal muscle tissue thereby lowering the toxicity induced by acid orange 7 . It has been reported that mixture of vitamins $\mathrm{C}$ and $\mathrm{E}$ ameliorated the toxic effects of zinc oxide nanoparticles in muscles of Nile tilapia [41].

Histopathology is one of the reliable methods for assessing the effects of environmental toxicants and health status of fish. Liver is the most important organ for detoxification and biotransformation of toxicants [42]. In the present study, acid orange 7 exposed for $96 \mathrm{~h}$ showed alterations in normal architecture of liver tissues such as degenerated and necrotic hepatocytes, and absence of nucleus. The observed cellular degeneration in hepatocytes could be associated to acid orange 7 induced stress responses. Similar observations were observed when the fish, Etroplus maculatus was exposed to lindane at sublethal concentration for 15 days [43]. Kidney of fish plays an important role in the excretion of toxicants, and also involved in the maintenance of homeostasis. In fish treated with acid orange 7 showed degeneration and necrosis of the proximal tubule and severe thrombosis. Tubular degeneration of kidney indicated the renal toxicity, which could prevent the infiltration of toxicants from the body of fish. Vitamin $\mathrm{C}$ exposure showed slight recovery of thrombosis, but the tubular necrosis 
retained in certain regions of the tissue. The present results were in agreement with another study on intraperitoneal exposure to fipronil in the Caspian white fish, Rutilus frisii [44]. Fish muscle is considered as most edible, nutritious and recommended food in the human nutrition due to low content of fat and high content of proteins and minerals along with optimal ratio of unsaturated fatty acids that possess cardio-protective effect. Conversely, fish muscle is the depositary for several toxicants that occur in the immediate environment [45]. The damage of muscle tissue observed after sublethal exposure of acid orange 7 reflected the harmful effects of the exposed dye. Vitamin $\mathrm{C}$ exposure for 7 days did not recover the histological damages in liver, kidney and muscle tissues caused due to the dye intoxication.

\section{CONCLUSION AND FUTURE SCOPE}

The present study clearly illustrated the sublethal toxicity of acid orange 7 in the fish, Anabas testudineus by unbalancing the pro-oxidant and antioxidant system in liver, kidney and muscle tissues. The data should be taken into account when the untreated industrial effluents are released into the aquatic ecosystems. The toxicity of dye was found to increase with the increase in time of exposure. Therefore, chronic exposure of azo dyes can surely cause adverse effects to the dwelling organisms in the ecosystem and could finally harm humans on exposure through the food chain. Further investigations are warranted on chronic bioassays from the environmentally polluted region so as to mimic the natural ecosystem. The data can be used as rapid and sensitive indicator for monitoring the risk assessment of toxicants on aquatic fauna, and finally the whole ecosystem. The protective role of vitamin $\mathrm{C}$ was also documented in the study by neutralizing the oxidative stress and improving the activities of tissuespecific marker enzymes. However, the histomorphological damages were not completely reversed to normal within 7 days of vitamin $\mathrm{C}$ exposure, and treatment for more duration is expected for the recovery. Therefore, by extending the duration of vitamin $\mathrm{C}$ exposure can ameliorate the histological damage induced by acid orange 7 .

\section{Table 1 Effect of acid orange7 on enzymatic antioxidants} in the fish, Anabas testudineus

\begin{tabular}{|llllllll|}
\hline Tissues & Group & SOD & \multicolumn{3}{ll}{ CAT } & \multicolumn{3}{l|}{ GR } & \\
\hline Muscle & Control & $2.30 \pm 0.02$ & $5.80 \pm 0.07$ & $8.44 \pm 0.08$ \\
& Vitamin & 2.19 & \pm & 5.67 & \pm & 6.43 & \pm \\
& C & $0.05^{*}$ & & $0.14^{*}$ & & $0.05^{*}$ & \\
& $24 \mathrm{~h}$ & 1.43 & \pm & 3.47 & \pm & 5.80 & \pm \\
& & $0.07^{*}$ & & $0.05^{*}$ & & $0.06^{*}$ & \\
& $72 \mathrm{~h}$ & 1.43 & \pm & $2.78 \pm 0.1^{*}$ & 2.84 & \pm \\
& & $0.01^{*}$ & & & & $0.15^{*}$ & \\
& $96 \mathrm{~h}$ & 1.27 & \pm & 1.65 & \pm & 2.47 & \pm \\
& & $0.02^{*}$ & & $0.06^{*}$ & & $0.05^{*}$ & \\
\hline Kidney & Control & $2.53 \pm 0.08$ & $6.53 \pm 0.12$ & $5.48 \pm 0.08$ \\
& Vitamin & 2.78 & \pm & $6.51 \pm 0.1^{*}$ & 5.24 & \pm \\
& C & $0.09^{*}$ & & & & $0.07^{*}$ & \\
& $24 \mathrm{~h}$ & 2.13 & \pm & 2.66 & \pm & 2.91 & \pm \\
& & $0.03^{*}$ & & $0.06^{*}$ & & $0.05^{*}$ & \\
& $72 \mathrm{~h}$ & 1.91 & \pm & 2.02 & \pm & 1.78 & \pm \\
& & $0.03^{*}$ & & $0.04^{*}$ & & $0.05^{*}$ & \\
& $96 \mathrm{~h}$ & 1.37 & \pm & 1.78 & \pm & 1.16 & \pm \\
& & $0.01^{*}$ & & $0.08^{*}$ & & $0.01^{*}$ & \\
\hline Liver & Control & $2.10 \pm 0.17$ & $7.67 \pm 0.31$ & $5.60 \pm 0.2$ \\
& Vitamin & 2.25 & \pm & $7.73 \pm 0.27$ & $7.36 \pm 0.2^{*}$ \\
& C & $0.21^{*}$ & & & & & \\
& $24 \mathrm{~h}$ & 1.72 & \pm & 5.57 & \pm & 5.03 & \pm \\
& & $0.08^{*}$ & & $0.15^{*}$ & & $0.03^{*}$ & \\
& $72 \mathrm{~h}$ & 1.57 & \pm & 3.18 & \pm & $4.11 \pm 0.1^{*}$ \\
& & $0.21^{*}$ & & $0.09^{*}$ & & & \\
& $96 \mathrm{~h}$ & 1.40 & \pm & 2.49 & \pm & 3.97 & \pm \\
& & $0.08^{*}$ & & $0.07^{*}$ & & $0.08^{*}$ & \\
\hline
\end{tabular}

SOD: superoxide dismutase; Unit: nmol pyrogallol oxidized/ $\mathrm{min} / \mathrm{mg}$ protein

CAT: catalase; Unit: $\mathrm{nmol} \mathrm{H}_{2} \mathrm{O}_{2}$ consumed/ $\mathrm{min} / \mathrm{mg}$ protein GR: glutathione reductase; Unit: nmol NADPH oxidized/ $\mathrm{min} / \mathrm{mg}$ protein

Data are expressed as mean \pm S.D. ( $n=10$ / group). Asterisks (*) denotes significant at $\mathrm{P}<0.05$ against the control group. 


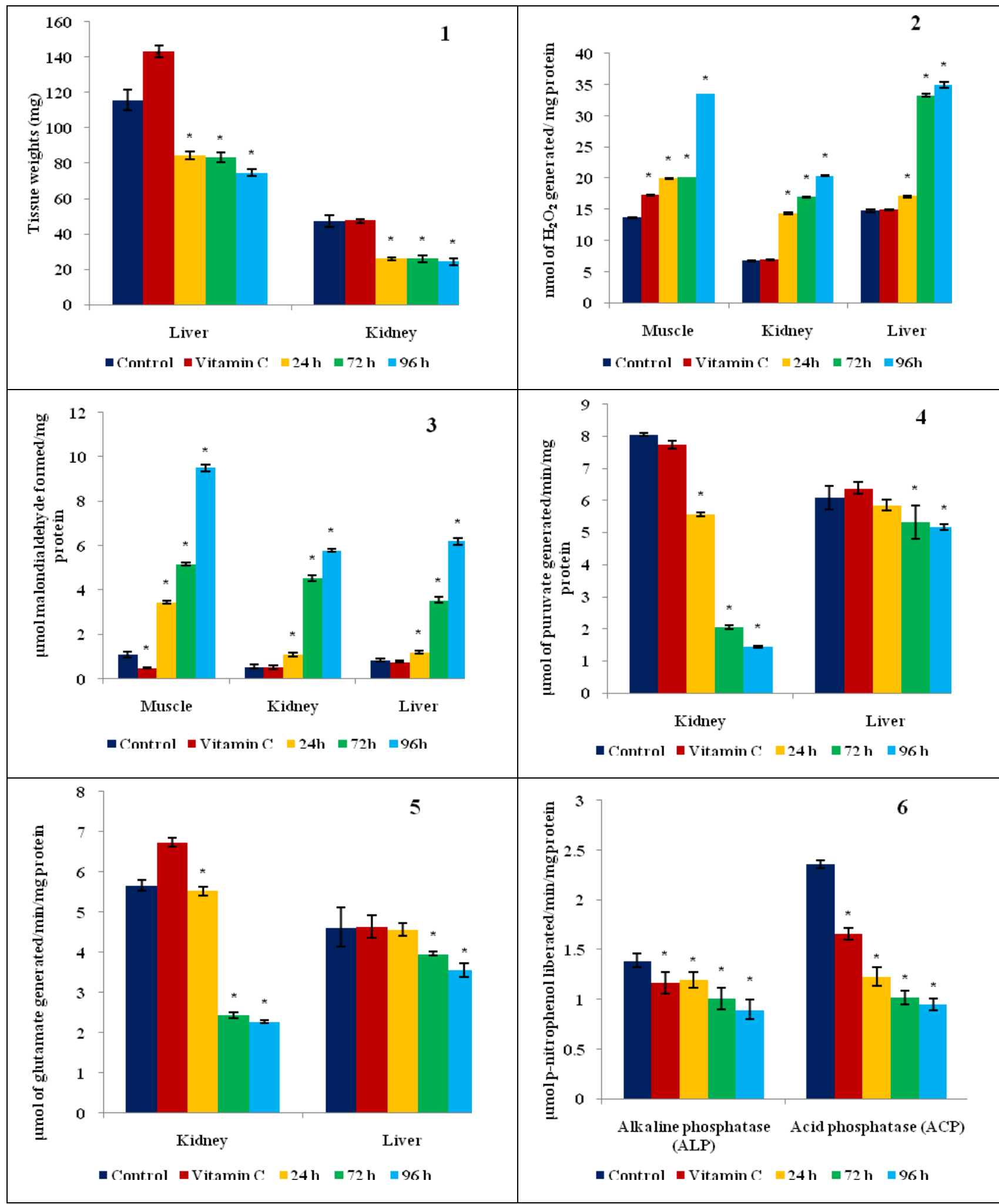

Figures1-6

Effects of acid orange 7 on 1) the tissue weights of the fish, Anabas testudineus; 2) level of hydrogen peroxide generation; 3) level of lipid peroxidation; 4) the activity of alanine aminotransferase; 5) activity of aspartate aminotransferase; 6) activities of alkaline and acid phosphatase in the fish, Anabas testudineus. $n=10$ fish/group; Data expressed as mean \pm standard deviation (SD); Asterisks (*) denotes significant at $P<0.05$ against the control group. 

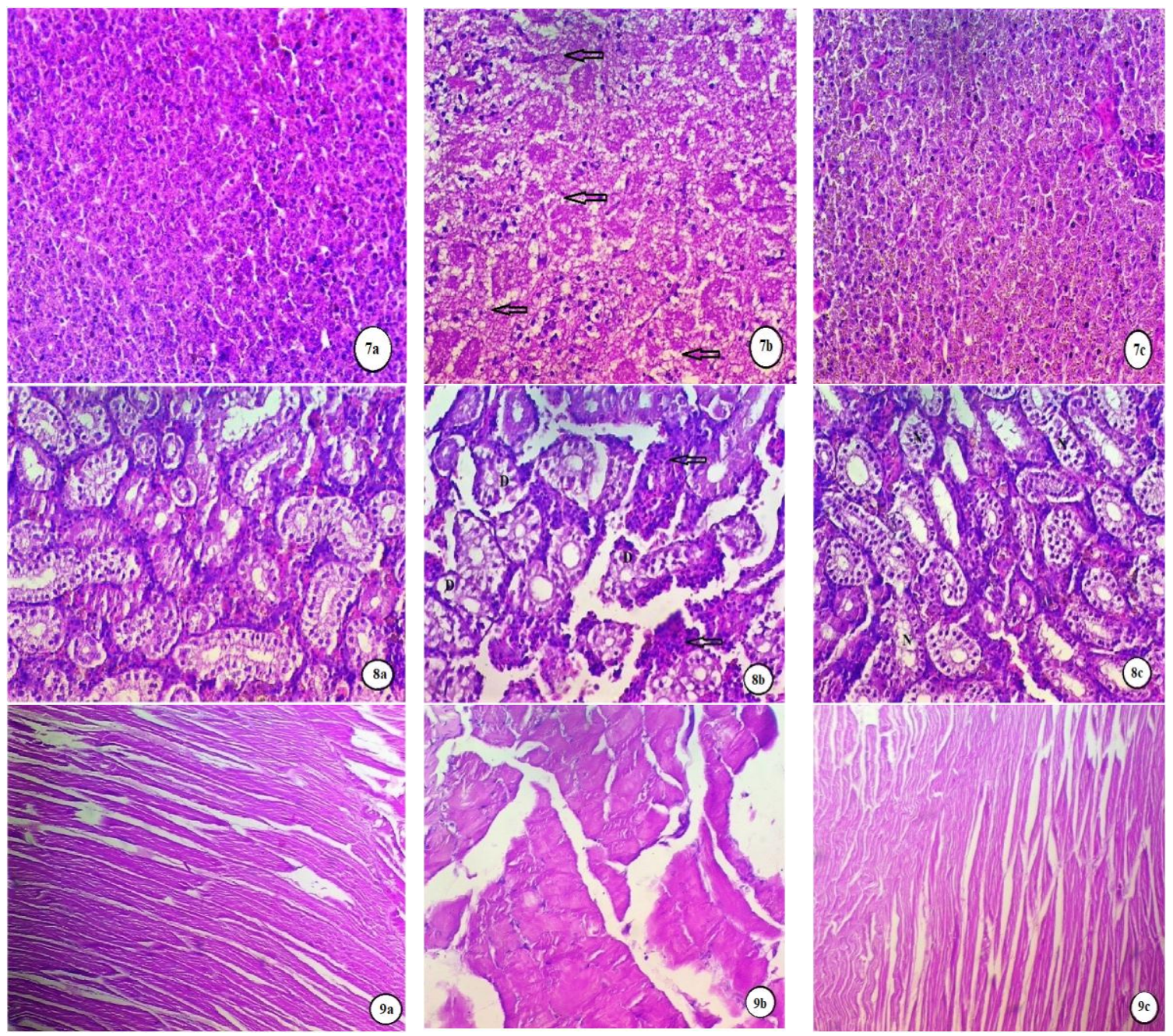

Figures 7-9

Histomorphology of 7a) Control liver tissues of Anabas testudineus showing normal histoarchitecture (H \& E - 400X); 7b) Acid orange 7 exposed liver tissues showing degenerated and necrotic hepatocytes (arrow), and absence of nucleus; 7c) Vitamin C exposed liver tissues after the dye exposure showing prominent nucleus in the hepatocytes; 8a) Control kidney tissue showing normal histoarchitecture; 8b) Acid orange 7 exposed kidney tissue showing degeneration (D) and necrosis of the tubule, and severe thrombosis (arrow); 8c) Vitamin C exposed kidney tissue after the dye exposure showing slight recovery but necrosis in tubule was retained in certain regions of the tissue; 9a) Control muscle tissue showing normal histoarchitecture; 9b) Acid orange7 exposed muscle tissue showing flaccid and degenerated muscles; 9c) Vitamin C exposed muscle tissue showing normal histoarchitecture.

\section{ACKNOWLEDGMENT}

The authors are thankful to Kerala State Council for Science, Technology and Environment, Government of Kerala, India for providing financial support.

\section{REFERENCES}

[1] I.S.Semenovich, "Water pollution and its impact on fish and aquatic invertebrates", Interactions: Food, Agriculture and Environment, Vol.1,Issue.1, pp. 1-6, 2009.

[2] M.Akhteruzzaman, A. H. M. Kohinoor, M. S.Islam, P. C. Modak, "Observations on the induced breeding of indigenous small fish Bhagna (Cirrhinus reba Ham.) in Bangladesh", Progressive Agriculture, Vol.9, Issue.1-2, pp.281-284,1998.
[3] R.Kumar, R.D.Singh, K.D. Sharma, "Water resources of India", Current Science, Vol.89, Issue.,5, pp794-811, 2005.

[4] R.Kant, "Textile dyeing industry an environmental hazard" Natural Science, Vol.4, Issue.1, 22-26, 2012.

[5] J.Hill, A.Okonski, B.Aikawa, S.Blechinger, M.Gagne, K.Hughes, "First stages in the ecological and human health assessment of aromatic azo and benzidine-based compounds on Canada's domestic substances list" in 32nd Society of Environmental Toxicology and Chemistry (North America) Meeting, Boston, MA, USA, 2011.

[6] N.Nagalakshmi, M.N.V.Prasad, "Copper-induced oxidative stress in Scenedesmus bijugatus: protective role of free radical scavengers", Bulletin of Environmental Contamination and Toxicology, Vol.61,Issue.5, pp.623-628, 1998.

[7] B.N.Tripathi, J.P.Gaur, "Relationship between copper-and zincinduced oxidative stress and proline accumulation in Scenedesmus sp”, Planta, 219,Issue. 3, pp.397-404, 2004. 
[8] D.Dewez, L.Geoffroy, G.Vernet, R. Popovic, "Determination of photosynthetic and enzymatic biomarkers sensitivity used to evaluate toxic effects of copper and fludioxonil in alga Scenedesmus obliquus" Aquatic Toxicology, Vol.74, Issue.2. Pp.150-159, 2005.

[9] L.Cao, W.Huang, J.Liu, X.Yin, S.Dou, “Accumulation and oxidative stress biomarkers in Japanese flounder larvae and juveniles under chronic cadmium exposure" Comparative Biochemistry and Physiology Part C: Toxicology and Pharmacology ,Vol.151, Issue.3, pp.386-392, 2010.

[10] S.Pandey, S.Parvez, I.Sayeed, R.Haque, B.Bin-Hafeez, S.Raisuddin, "Biomarkers of oxidative stress: a comparative study of river Yamuna fish Wallago attu (B1. \& Schn.)", Science of the Total Environment, Vol.309, Issue.1-3, 105-115, 2003.

[11] S.A.Dar, P.P.Srivastava, T.Varghese, M.I.Nazir, S.Gupta, G.Krishna, "Temporal changes in superoxide dismutase, catalase, and heat shock protein 70 gene expression, cortisol and antioxidant enzymes activity of Labeo rohita fingerlings subjected to starvation and refeeding", Gene,Vol.692, pp.94-101, 2019.

[12] D.E.Hinton, D.J.Laure'n, "Liver structural alterations accompanying chronic toxicity in fishes: potential biomarkers of exposure, Lewis Publishers, pp.17-57, 1990.

[13] A.Figueiredo-Fernandes, A.Fontaínhas-Fernandes, E.Rocha, M.A.Reis-Henriques, "The effect of paraquat on hepatic EROD activity, liver, and gonadal histology in males and females of Nile Tilapia, Oreochromis niloticus, exposed at different temperatures" Archives of Environmental Contamination and Toxicology, Vol.51,Issue. 4,pp. 626-632, 2006.

[14] APHA, "Standard methods for the examination of water and waste water", Washington, D.C. : APHA-AWWA-WEF Publisher, 1998.

[15] S.Marklund, G.Marklund, "Involvement of the superoxide anion radical in the autoxidation of pyrogallol and a convenient assay for superoxide dismutase" European Journal of Biochemistry, Vol. 47, Issue. 3, pp. 469-474, 1974

[16] A.Claiborne, "Catalase activity", CRC Press Publisher, pp.283284, 1985.

[17] I.N.C.E.R.Carlberg, B.E.N.G.T. Mannervik, "Purification and characterization of the flavoenzyme glutathione reductase from rat liver", The Journal of Biological Chemistry, Vol.250, Issue.14, pp.5475-5480, 1975.

[18] E.Pick, Y.Keisari, "Superoxide anion and hydrogen peroxide production by chemically elicited peritoneal macrophagesinduction by multiple nonphagocytic stimuli", Cellular Immunology, Vol. 59, Issue. 2, pp.301-318, 1981.

[19] H.Ohkawa, N.Ohishi, K.Yagi, "Assay for lipid peroxides in animal tissues by thiobarbituric acid reaction", Analytical Biochemistry, Vol.95, Issue.2, pp. 351-358, 1979.

[20] S.Reitman, S.Frankel, "A colorimetric method for the determination of serum glutamic oxalacetic and glutamic pyruvic transaminases", American Journal of Clinical Pathology, Vol.28, Issue.1, pp. 56-63, 1957.

[21] O.A.Bessey, O.H.Lowry, M.Beock, J.A.Lofez, "The determination of vitamin A and carotene in small quantities of blood serum", The Journal of Biological Chemistry, Vol.166, pp.177-188, 1946.

[22] O.H.Lowry, N.J.Rosebrough, A.L.Farr, R.J.Randall, "Protein measurement with the Folin phenol reagent", The Journal of Biological Chemistry, Vol. 193, pp.265-275, 1951.

[23] R.J.Roberts, D.A.Smail, "Fish pathology", Harcourt Publishers Limited., pp380-390, 2001.

[24] I.M. Banat, P.Nigam, D.Singh, R.Marchant, "Microbial decolorization of textile-dye-containing effluents: A review", Bioresource Technology, Vol.61, Issue.1, pp.103-103, 1997.

[25] J. M.Law, " Issues related to the use of fish models in toxicologic pathology: session introduction", Toxicological Pathology, Vol.31, pp.49-52, 2003.
[26] S.Pandey, S.Parvez, I.Sayeed, R.Haque, B.Bin-Hafeez, S.Raisuddin, "Biomarkers of oxidative stress: a comparative study of river Yamuna fish Wallago attu (B1. \& Schn.)", Science of the Total Environment, Vol.309, Issue.1-3,105-115, 2003.

[27] D.Harman, "Free radical involvement in aging", Drugs and Aging, Vol.3, pp.60-80, 1993.

[28] A.Valavanidis, T.Vlahogianni, M.Dassenakis, M.Scoullos, "Molecular biomarkers of oxidative stress in aquatic organisms in relation to toxic environmental pollutants", Ecotoxicology and Environmental Safety, Vol.64, Issue.2, pp.178-189, 2006.

[29] H.Sies, "Strategies of antioxidant defense", European Journal of Biochemistry, Vol. 215, Issue. 2, pp.213-219, 1993.

[30] D.R.Janero, "Malondialdehyde and thiobarbituric acid-reactivity as diagnostic indices of lipid peroxidation and peroxidative tissue injury", Free Radical Biology and Medicine, Vol.9, Issue.6, pp.515-540, 1990.

[31] E.Lopez-Lopez, L.Favari, L.Martínez-Tabche, M.Madrigal, C.Soto, "Hazard assessment of a mixture of pollutants from a sugar industry to three fish species of western México by the responses of enzymes and lipid peroxidation" Bulletin of Environmental Contamination and Toxicology,Vol.70,Issue.4, pp.739-745, 2003.

[32] B.Halliwell, J.M.Gutteridge, "Free radicals in biology and medicine. Oxford University Press", USA, 2015.

[33] J.J.Thiele, H.J.Freisleben, J.Fuchs, F.R.Ochsendorf, Ascorbic acid and urate in human seminal plasma: determination and interrelationships with chemiluminescence in washed semen. Human Reproduction, Vol.10,Issue.1, pp.110-115, 1995.

[34] R.M.Wells, R.H.McIntyre, A.K.Morgan, P.S.Davie, "Physiological stress responses in big gamefish after capture: observations on plasma chemistry and blood factors", Comparative Biochemistry and Physiology- A; Comparative Physiology, Vol.84, Issue.3, pp.565-571, 1986.

[35] M.A.Mousa, Y.A.Khattab, "The counteracting effect of vitamin C (L-ascorbic acid) on the physiological perturbations induced by ochratoxin intoxication in the African catfish (Clarias gariepinus)", Journal of Egyptian Academic Society for Environmental Development (D-Environmental Studies), Vol. 4, Issue.1, pp.1117-128, 2003.

[36] S.R.Verma, S.Rani, R.C.Dalela, "Effects of phenol and dinitrophenol on acid and alkaline phosphatases in tissues of a fish (Notopterus notopterus)", Archives of Environmental Contamination and Toxicology, Vol.9, Issue.4, pp.451-459, 1980.

[37] P.P.Srivastava, A.Chaudhuri, K.Damodar Reddy, K.Thangavelu, R.K.Prasad, "Purification and characterization of alkaline phosphatase from fat body of tropial tasar silkworm, Anthemea mylitta Drury", Indian Journal of Experimental Biology, Vol.33, pp.284-286, 1995.

[38] K.Parthasarathi, R.Karuppasamy, "Fenvalerate Impact on Tissue Acid and Alkaline Phosphatase Activity of the Fish, Chahna Punctatus (Bloch)", Pollution Research, Vol.17, pp.281-285, 1998.

[39] S.Goldfischer, E.Essner, A.B.Novikoff, "The localization of phosphatase activities at the level of ultrastructure", Journal of Histochemistry and Cytochemistry, Vol.12, Issue.2, pp.72-95, 1964.

[40] A.Srivastava, U.Kumari, A.K.Nigam, S.Mittal, A.K.Mittal, "Alterations in the activity of certain enzymes in the gills of a carp Labeo rohita exposed to an azo dye, Eriochrome black T: a biochemical investigation", Fish Physiology and Biochemistry, Vol.44, Issue.2, pp.629-637, 2018.

[41] A.M.Abdelazim, I.M.Saadeldin, A.A.Swelum, M.M.Afifi, A.Alkaladi, "Oxidative stress in the muscles of the fish Nile tilapia caused by zinc oxide nanoparticles and its modulation by vitamins C and E", Oxidative Medicine and Cellular Longevity, Vol.2018, pp.1-9, 2018. 
[42] R.Van der Oost, J.Beyer, N.P.Vermeulen, "Fish bioaccumulation and biomarkers in environmental risk assessment: a review. Environmental Toxicology and Pharmacology", Vol.13, Issue.2, pp.57-149, 2003.

[43] S.B.Nandan, P.J.Nimila, Lindane toxicity: Histopathological, behavioural and biochemical changes in Etroplus maculatus (Bloch, 1795). Marine Environmental Research, Vol.76, pp.63-70, 2012.

[44] R.A.Ardeshir, H.Zolgharnein, A.Movahedinia, N.Salamat, E.Zabihi, "Comparison of waterborne and intraperitoneal exposure to fipronil in the Caspian white fish (Rutilus frisii) on acute toxicity and histopathology", Toxicology Reports, Vol. 4, pp.348357, 2017.

[45] J.Andreji, P.Dvorak, Z.Dvorakova-Liskova, P.Massanyi, T. Stranai, P.Nad, M.Skalicka, "Content of selected metals in muscle of cyprinid fish species from the Nitra River, Slovakia," Neuroendocrinology Letters, Vol.33, pp.84-89, 2012.

\section{AUTHORS PROFILE}

C. V. Priyatha obtained M. Sc in Applied Zoology and presently pursuing $\mathrm{Ph}$. D in the Department of Zoology, University of Calicut, Kerala, India, in the area of Aquatic Toxicology. She has qualified the Kerala State Council for Science Technology and Environment Research Fellowship examination.

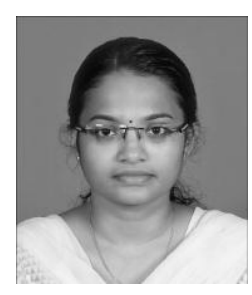

K. C. Chitra is presently working as Associate Professor in the Department of Zoology, University of Calicut, India. 